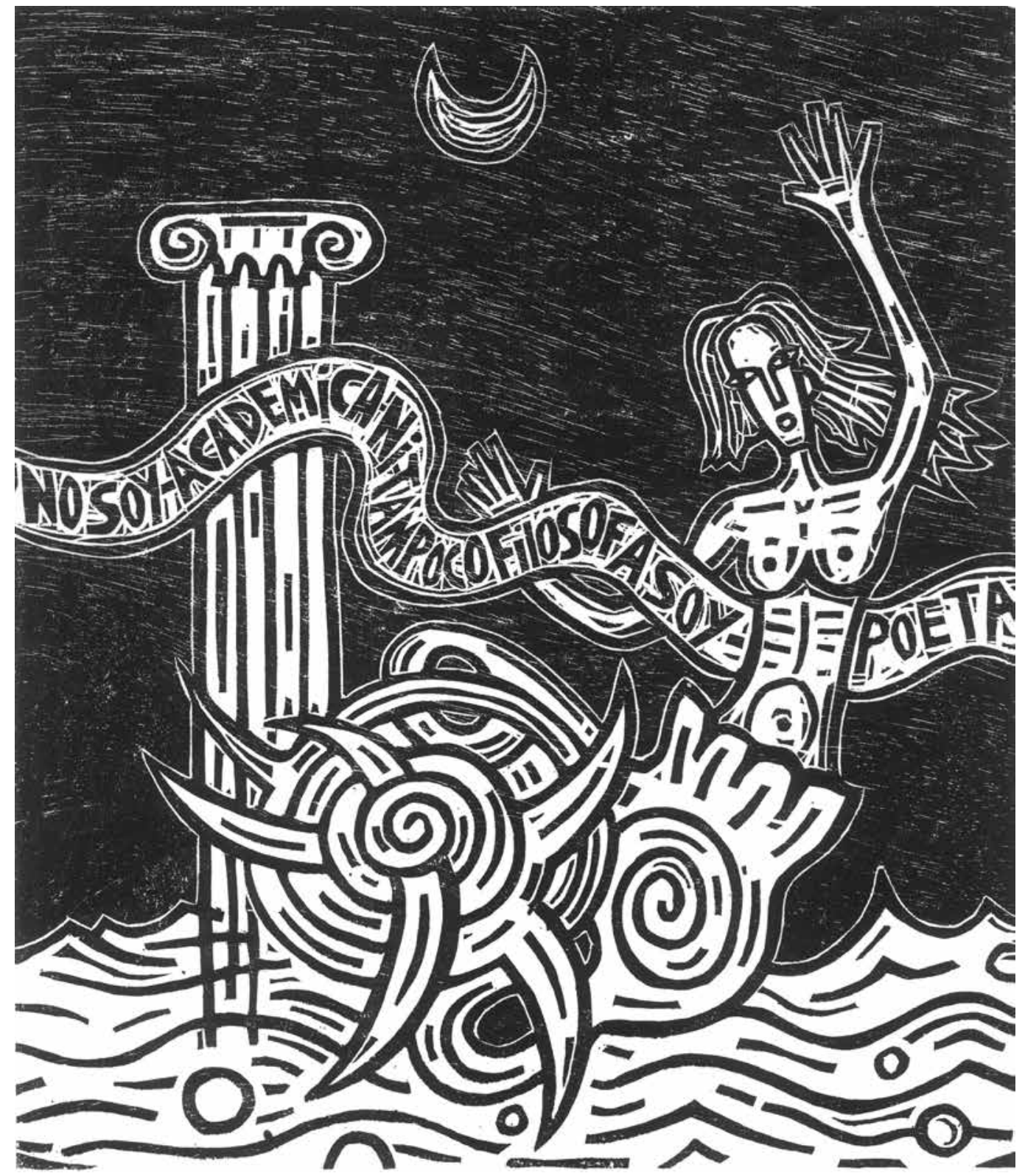

Ilustración de Hernán Arévalo Solórzano

"Sin título"

Xilografía

$30 \times 20 \mathrm{~cm}$

2017 


\section{Una lectura de La tumba de Antígona de María Zambrano*}

Mia Gallegos Domínguez.

A Myriam Bustos Arratia, símbolo de la piedad. A Roberto Murillo Zamora, símbolo del pensar.

A Francisco Álvarez González, maestro.

$\mathbf{M}$ uchas gracias, señora Estrellita Cartín de Guier, muchas gracias a todos los miembros de la Academia Costarricense de la Lengua por haber incluido mi nombre en esta imprescindible institución que tan buenos frutos le ha dado a nuestro país.

Con sorpresa, y también con un enorme compromiso, he aceptado trabajar al lado de ustedes en la hermosa tarea de mantener viva nuestra lengua, lengua que se dice es para hablar con Dios... en especial si pensamos en San Juan de la Cruz y Teresa de Ávila... y también en la voz de María Zambrano, que se enrumba por la vía de lo sagrado, autora que ilumina las palabras que pronuncio en esta ocasión.

Al principio, cuando se me habló de unirme a las labores que la Academia desempeña, tuve un sentimiento de incertidumbre. Mil ideas surcaron por mi mente y, sobre todo, la incógnita de qué tema, inspirador y pleno, podría llevar al seno de esta casa que hoy me acoge. Entonces me detuve a pensar en cuál había sido el camino recorrido, el camino escogido, o quizás apenas insinuado, el camino colmado de tropiezos, serpenteante, como ha sido el mío en el campo de las letras y de la vida. En ese sendero aparecieron ante mí nombres, encrucijadas, bifurcaciones y la certeza única de haber hallado una madre símbolo de la sapiencia: vi ante mí la mano abierta, la mano guía de María Zambrano alumbrando el camino, ella, con la luz que acompaña siempre sus escritos, con la luz propia del pensamiento auroral.

Mientras meditaba en este discurso que ahora pronuncio, evoqué a mi viejo y sabio profesor de filosofía: Francisco Álvarez González, discípulo de José Ortega y Gasset al igual que María Zambrano. Pero era ya tarde para llamarlo y pedirle consejo: el maestro había

* Discurso de incorporación a la Real Academia de la Lengua de Costa Rica, 27 de octubre de 2015. 
muerto en la ciudad de Heredia hacía dos años, de modo que era indispensable que buscara sus huellas en los libros que nos heredó, en su pensamiento, en la lectura acuciosa de los presocráticos y de otros que él tanto conocía.

Tampoco podía llamar al filósofo Roberto Murillo, quien fue miembro de esta Academia Costarricense de la Lengua, y nos ha dejado una herencia valedera y que quizás deba esta institución, en conjunto con las universidades estatales, rescatar del olvido lo más valioso de su pensamiento. Y digo olvido, ya que esa es la realidad a la que van los hombres y mujeres de letras de nuestro país porque es costumbre echar tierra sobre sus obras.

Pero quedaba ahí -silenciosa y presente siempre-, mi amiga Myriam Bustos Arratia, una Antígona, una exiliada, una mujer que enfrentó, al igual que María Zambrano, una dictadura y el destierro. Mas, Myriam representa la piedad, esa piedad de la que con tanta hondura nos habla María Zambrano en buena parte de sus escritos y a la que en párrafos posteriores voy a referirme.

La pasión intelectual y vital que me une a la Zambrano fue un vínculo que empezó a tejerse desde siempre. En mi juventud, una cubana, Oliva Espín, me quemó con el fuego sagrado, pues me dio a conocer a los grandes trágicos. No sabía en esa época que la vocación por el pensamiento mítico iba a acrecentarse a través de toda mi existencia. Ignoraba también en esa época, que por razones que no viene al caso explicar, era la mía una sensibilidad trágica, tal y como la entiende Miguel de Unamuno.
Juventud, sí; mi juventud, una mocedad vivida durante la época de la guerra fría y su posterior culminación. Una juventud colmada de rebeldía, de enfrentamientos, de lecturas, de sed infinita por el conocimiento. Fui y sigo siendo, para decirlo de la manera más exacta posible, una lectora desbordada. Además, debo decir que en ocasiones, también fui una joven enmurada, y quizás por eso amo tanto a Antígona... Ahí, adentro, en esa llama íntima, en esa llama que solo yo sentía palpitar, se abrigaban fuertes pensamientos: ¿Por qué la filosofía y la poesía se separaron? ¿Cómo? ¿Cuándo? ¿Dónde? ¿Por qué? Solamente me bastó saber que Platón excluyó a los poetas de La República ideal... entonces empecé a explicarme lo que acontecía aún hoy.

No me atreví jamás a formularle estas preguntas a nadie, ocupada siempre en resolver problemas inmediatos. Atareada en mil faenas, las dudas seguían bullendo ahí dentro y no sabía a quién plantearle estos dilemas de proporciones mayúsculas.

Aquí, debo detenerme unos instantes: no soy filósofa y tampoco académica: soy poeta. En todo caso, para decirlo con palabras de Rimbaud, como Juana de Arco, soy de las que cantan a la hora del suplicio. No obstante, al igual que los presocráticos siempre me han inquietado el origen y el ser de las cosas. He querido saber quién soy yo, si es que cabe responderse esa interpelación. Y al plantearme todas esas interrogantes, he acudido a los libros, he procurado llegar a las fuentes, y he intentado reconocerme, aunque sea modestamente, en estas y muchas otras inquietudes. 
En 1985, en plena guerra centroamericana, viajé a los Estados Unidos: una beca para escribir me llevó a Iowa, ciudad donde permanecí durante tres meses. Y escribí y también entablé una hermosa amistad con la escritora mexicana Verónica Volkow, quien al leer mis poemas de entonces, me dijo que estaba en la obligación de leer a María Zambrano, a quien yo no conocía. No leí entonces a la filósofa española; en realidad pasaron muchos años para que encontrara en alguna librería josefina obras suyas. Sin embargo, ahí quedó guardada la idea en la penumbra del pensamiento.

Meses después, de vuelta en tierra natal, tuve el privilegio de estudiar un curso en torno a los filósofos presocráticos que impartía Francisco Álvarez González y todo empezó a iluminarse. De pronto vi ante mí los nombres de Tales de Mileto, Anaxímenes, Anaximandro, Heráclito, Empédocles... y muchas intuiciones que había guardado celosamente en mi interior empezaron a cobrar vida. Me ocurrió lo que con tanto acierto detalla María Zambrano en su libro Hacia un saber sobre el alma: "Pero sucede que esa filosofía "camino de vida", camino de salvación, se introduce en el alma violentamente, sin guía, sin método" (1993:66).

Así, entonces, de manera violenta, me inició Francisco Álvarez en los conceptos de rarefacción, apeiron, arjé, hybris, physis... A pesar de ello, ese deleite, ese privilegio de haber hallado a un maestro no duró mucho tiempo. La realidad, como una puerta de goznes rigurosos, se impuso y me obligó, una vez más, a cambiar de derrotero.
Esos años también fueron ricos en las lecturas de Carl Gustav Jung, de manera que el libro intitulado Los días y los sueños, cuadernillo de sueños que escribí en Iowa, además de mitológico, me obligó a realizar descensos y búsquedas en esa región anterior a la palabra. Fue una faena con la sombra, en la cual he permanecido trabajando fielmente durante varios años. Ignoraba entonces, que ese pequeño libro, un libro que es en realidad el apunte de una aprendiz, me iba llevar, muchos años después, a comprender los escritos de María Zambrano, en especial, la razón poética y los temas que ella trata en torno al sueño creador.

De manera que debo disculparme por haberme extendido en estos comentarios: este preámbulo era imprescindible, para hablar, a partir de ahora, sobre el tema esbozado al principio: La tumba de Antigona, vista a la luz de sus concepciones filosóficas, especialmente las que ella recoge en su obras: El hombre y lo divino, Filosofia y poesía y en Hacia un saber sobre el alma.

Todos los años dedico unos días para releer a los trágicos griegos, y de manera especial la Antígona de Sófocles, mi obra favorita. No voy a referirme a la escrita por el trágico; no obstante, de ser necesario estableceré vínculos entre la del griego y la que nos presenta María Zambrano.

Cuando leí por primera vez La tumba de Antígona, a mediados de los años noventa, me encontré con una obra cuyo final no es la muerte de la joven... Cuando terminé de leerla no comprendí a cabalidad la interpretación que la autora había hecho de este mito. Y es que para María Zambrano, 
Antígona no se suicida, sino que se transfigura. Aquí es necesario resaltar que Zambrano le da una solución mística al conflicto de Antígona. Es precisamente en este punto en el que se puede apreciar el surgimiento de una conciencia naciente que da paso a la filosofía. Para María Zambrano, Antígona es "la muchacha que llora enterrada viva en su sepulcro impenetrable. Y su llanto es agua; llanto de una herida que nadie descubre, sobre la que nadie se inclina a beber; la vida misma en su presencia primera; el agua" (1993: 195).

Debo decir que la primera lectura de esta obra me produjo una suerte de extrañamiento; supe desde el principio que iba a necesitar leerla muchas veces para captar toda la profundidad que encierra. De manera que en ese transitar por su obra, surgió una emoción que se ha mantenido desde la primera lectura: descubrir que las palabras llegaron a un sitio, a un centro, que no es necesariamente la inteligencia; no, María Zambrano penetró una zona que yo ignoro cómo definirla, cómo llamarla, ya que produce un íntimo deleite y sobre todo, pasmo, palabra que la filósofa utiliza con frecuencia para describir lo que sucede en las entrañas de los poetas. Sin duda, al leer los textos de Zambrano también participé de la "liturgia" propia de la tragedia.

De manera que atrapada por el símbolo de Antígona, me he detenido una y otra vez en estos textos que conforman el libro de Zambrano. Mas también evoco al maestro Mircea Eliade, quien dice que

Vivir los mitos implica, pues, una experiencia verdaderamente "religiosa", puesto que se distingue de la experiencia ordinaria, de la vida cotidiana. La "religiosidad" de esta experiencia se debe al hecho de que se reactualizan acontecimientos fabulosos, exaltantes, significativos; se asiste de nuevo a las obras creadoras de los Seres Sobrenaturales; se deja de existir en el mundo de todos los días y se penetra en un mundo transfigurado, auroral, impregnado de la presencia de los Seres Sobrenaturales (2001:11).

Mas como los símbolos y los mitos se resemantizan, la luminosa conciencia de Antígona siempre tendrá impacto sobre la vida y la psique de hombres y mujeres de todos los tiempos, y en particular esta versión de Zambrano, cuyos personajes son plenamente humanos. Aquí debo repetir con vehemencia las propias palabras de María Zambrano quien dice que: "El mundo sagrado es la realidad desnuda, hermética, sin revelar" (1973: 209). Ese es el mundo que nos revela Antígona, un orden donde los dioses han abandonado a los hombres y estos sienten su desamparo. También es el despliegue de la conciencia entre la vida y la muerte.

Tal y como lo apunta Gemma del Olmo Campillo, en su ensayo titulado La voz de Antígona: entre la vida y la muerte,

es un viaje de vuelta a los orígenes de la filosofía, cuando la razón occidental todavía no había tomado el camino de la soberbia, cuando todavía acogía la incógnita en las afirmaciones, los interrogantes y la admiración por la naturaleza. Cuando la razón no pretendía dar cuenta 
de todo ni construía sistemas categóricos en los que comprender y fijar todo conocimiento. (2014)

Y añade: "Zambrano apuesta por una realidad cambiante que no puede estructurarse en un sistema inmutable ni ajustarse en parámetros que ejercen violencia sobre lo real. La realidad excede cualquier intento por asirla y atraparla" (2014)

La Antígona de Zambrano es distinta de la creada por Sófocles. Por una parte, la heroína de Sófocles se rebela contra el tirano; en cambio, la de Zambrano es una joven de sumisa condición: su fuerza y la fascinación que ejerce sobre el lector son su delirio, su expresión poética, su pensar, su capacidad de ensimismamiento, ese musitar y exclamar desde el fondo de las entrañas, lo que nos deslumbra es su descenso, su viaje a los infiernos del alma.

La tumba de Antígona, de María Zambrano, no fue concebida para ser representada: es una obra para ser leída. En realidad, se trata de un escrito de prosa poética, donde también hay diálogos. Pese a ello, en España, su tierra, esta obra sí ha sido llevada a escena. Su estructura consta de doce partes, en las cuales intervienen distintos personajes: Edipo; Antígona; Ana, la nodriza; los hermanos; la hermana; la madre, Hemón; Creón y, finalmente, dos desconocidos.

La obra, que he leído ya en numerosas ocasiones, fue publicada por la Editorial Mondadori y en ella se reproduce una introducción escrita por Julia Castillo, además de un ensayo sobre Antígona de María Zambrano. La autora, quien fue escribiéndola a lo largo de muchos años de exilio, siempre pensó que la Antígona a quién ella presenta, es su hermana Araceli, su única hermana, que la acompañó durante todo el exilio, un exilio que las llevó a vivir a ambas en tierras americanas: Cuba, Morelia en México, Puerto Rico y, posteriormente, en Italia, Suiza y Francia.

Es de su propia biografía de donde parte para construir esta Antígona, desterrada y exiliada, símbolo o metáfora de la piedad. Araceli, quien estuvo casada, perdió a su esposo, quien fue asesinado con la llegada de Francisco Franco al poder luego de derrotar a los combativos republicanos. De manera que la autora nos habla en estas páginas desde un saber de experiencia, desde un saber filosófico y desde un saber poético. Mas nos habla, por sobre todo, desde el destierro. Y aun más: nos permite presenciar la antigua escisión y también el feliz encuentro entre la poesía y la filosofía, tal y como intentaré explicar en los párrafos siguientes.

Y aquí, quiero citar de manera literal, un fragmento del ensayo escrito por Zambrano en relación con este libro:

Antígona es una figura, un tanto profética - del profetismo griego-, de esta pasión. Su sacrificio, por ser obra de amor, abarca los tres mundos en toda su extensión. El de los muertos, a los que su piedad la lleva; una piedad-amor-razón que le dice que ha de estar entre ellos más que entre los vivos, como si su vida sobre la tierra se le apareciese como una efímera primavera; como si ella fuera una Perséfone sin esposo que ha obtenido únicamente una estación: una 
primavera que no puede ser reiterada. El mundo propiamente terrestre donde ha nacido en el laberinto de unas entrañas como sierpes; en el laberinto de la guerra civil y de la tiranía subsiguiente, es decir: en el doble laberinto de la familia y de la historia. Y alrealizar ella su sacrificio con la lucidez que le descubre la Nueva Ley, que es también la más remota y sagrada, la Ley sin más, llega hasta allí donde una humana sociedad exista. (1989: 20)

Sí; ciertamente, Antígona representa el sacrificio, un sacrificio que ella asume para desentrañar los lazos familiares que la convierten en hija y a la vez en hermana de su padre. Asimismo, representa la asunción de un sacrificio al enfrentarse con el poder. Es en estos enfrentamientos cuando surge la piedad. Y esta noción debe ser comprendida en los siguientes términos: ponerse en el lugar del otro, en este caso de sus hermanos, en especial de Polinices, víctima, como ella, de un nefasto e incestuoso origen familiar. Antígona y Polinices son doblemente víctimas, ya que se enfrentan al poder del tirano. Aquí, cabe precisar que todo el sacrificio que Antígona realiza es por la defensa de su hermano: de ahí la piedad, la hermandad y el ponerse justo en el lugar del otro.

No obstante, la lectura que yo emprendo en esta ocasión, me lleva a las primerísimas páginas de la obra, momento de inicio, en el cual Antígona delira: "Vedme aquí dioses, aquí estoy, hermano. ¿No me esperabas? ¿He de caer aún más bajo? Sí, he de seguir descendiendo para encontrarte. Aquí es todavía sobre la tierra. Y ese rayo de luz que se desliza como una sierpe, esa luz que me busca, será mi tortura mayor. No poder ni aun aquí librarme de ti, oh luz, luz del sol, del Sol de la Tierra" (1989).

$Y$ es que en este fragmento inicial, Antígona ya está en su tumba y toda la obra transcurrirá en este encierro, donde llegan a visitarla distintos personajes que son, en realidad, figuras fantasmagóricas. Tal parece que en toda la obra escrita de Zambrano, La tumba de Antígona rememora el mito de la caverna de Platón, aunque en este caso, ella en lugar de salir, ingresa en la tumba, después de haber vivido un proceso de anagnórisis, propio de las tragedias.

Antígona, además de realizar un sacrificio, representa el nacimiento de la conciencia. Como se puede apreciar en el texto transcrito, la joven increpa a los dioses, pero estos ya no están como solían antiguamente, porque se ha producido una mudanza significativa que va del mundo de la poesía al de la filosofía, es decir, el momento de la escisión. En diferentes partes de la obra, Antígona hace ver que los dioses ya no están. Y si se han marchado, queda solo la conciencia que se abre paso a la filosofía.

Precisamente, en otra obra de Zambrano que lleva el título de El hombre y lo divino, la autora se detiene a analizar el tránsito que hizo que estas dos manifestaciones del espíritu se separaran. Es así como la poesía va acompañada siempre del delirio, delirio que podemos percibir en las primeras palabras de Antígona. De ahí que es necesario detallar en qué consiste este delirio, ya que según sus palabras: En lo más hondo de la relación del hombre con 
los dioses anida la persecución: se está perseguido sin tregua por ellos y quien no sienta esta persecución implacable sobre y alrededor de sí, enredada en sus pasos, mezclada en los más sencillos acontecimientos, decidiendo y aun dictando los sucesos que cambiando su vida, torciendo sus caminos, latiendo enigmáticamente en el fondo secreto de su vida y de la realidad toda, ha dejado en verdad de creer en ellos." (1973: 27)

Antígona clama e increpa a los dioses, lamenta su abandono, y también invoca a su hermano. Los dioses se han ido, o quizás están por ahí semiocultos. Este primer canto es, por así decirlo, un delirio; sin embargo, no se trata de un aturdimiento como el que conocemos hoy día desde la perspectiva psicoanalítica. En realidad es un intento por hallar una respuesta en las fuerzas de la naturaleza que los griegos encarnaron en los dioses. Al mismo tiempo es fascinación y horror por lo sagrado. Estas dos emociones paradójicas son las que, en última instancia, producen el delirio.

Y aquí cabe mencionar el significado que Zambrano le da a este drama:

La tragedia griega es la madurez de este modo de expresión: conjuro, invocación, decires, que se repiten de tiempo inmemorial, lenguaje de la piedad; género clásico del mundo arcaico. Oficio de la piedad, del sentir que es hacer y conocer; expresión y fijación de un orden que da sentido a los sucesos indecibles; una forma de liturgia. (1973: 221)
Y, aunque Antígona está en la tumba, se pregunta si va a descender aún más. De manera que todo el texto, de principio a fin, muestra un descenso o catábasis. Es un descenso entre la vida y la muerte. No obstante, al propio tiempo, al cobrar Antígona conciencia de los males que la aquejan, tanto a ella como a su familia y a la ciudad, vivirá la experiencia de un segundo nacimiento, ahí mismo, en los albores de su muerte. La tumba, que no es solo el lugar de la muerte, adquiere, asimismo otras connotaciones, como cuando la joven dice: "No tumba mía, no voy a golpearte. No voy a estrellar contra ti mi cabeza. No me arrojaré sobre ti como si fueras tú la culpable: Una cuna eres; un nido. Mi casa. Y sé que te abrirás. Y mientras tanto, quizá me dejes oír tu música, porque en las piedras blancas hay siempre una canción" (1989).

Respecto del símbolo de la tumba vale la pena detenerse y reflexionar. De acuerdo con el Diccionario de los Símbolos de Jean Chevalier y Alain Gheebrant (1986), quienes en su acepción número dos citan al psicoanalista Carl Gustav Jung, autor, cuyo pensamiento se enlaza en muchísimos aspectos con el de María Zambrano, y dice así:

C.G. Jung relaciona la tumba con el arquetipo femenino, como todo lo que envuelve o enlaza. Es el lugar de la seguridad, del nacimiento, del crecimiento y de la dulzura; la tumba es el lugar de la metamorfosis del cuerpo en espíritu o del renacimiento que se prepara; pero es también el abismo donde el ser se sume en tinieblas pasajeras e ineluctables. 
$Y$ es que en este fragmento, como en toda la obra citada, María Zambrano alude a la razón poética, de la que ella dice es muy difícil, casi imposible hablar:

Es como si hiciera morir y nacer a un tiempo; ser y no ser, silencio y palabra, sin caer en el martirio ni en el delirio que se apodera del insomnio del que no puede dormirse, solamente porque anda a solas. ¿Lo llamaríamos desamparo? Tal vez. Terror de perderse en la luz más aún que en la oscuridad... (1989: 130)

No obstante, aunque Zambrano no explica en uno solo de sus libros en qué consiste la razón poética, sí se puede sistematizar su pensamiento al recorrer sus principales obras, como podrá notarse en las citas que realizo en este análisis, así como también es posible hallar una guía en su pensamiento, tema que unifica la autora en su obra Notas de un método (1989). Además, es preciso señalar que quien mejor comprende la síntesis realizada por la literata es el filósofo Jesús Moreno Sáenz.

Aquí es necesario destacar que Zambrano siempre manifestó en sus concepciones una crítica frente a la filosofía occidental pues, para ella, esta ha fracasado en su intento de rescatar el auténtico ser del hombre. El pensamiento racionalista no indaga en las entrañas, tal como ella lo propone a lo largo de todos sus escritos. De manera que vuelve su mirada al sentir originario para luego retornar a una realidad consciente y reflexiva. Lo que busca primordialmente es la revelación y un renacimiento constantes.
En este sentido es necesario evocar la Teogonía de Hesiodo en la que se menciona que tanto Afrodita, diosa del amor humano, como las Euménides, diosas del sufrimiento, tienen un origen común, ya que ambas nacen en las entrañas. De ahí que cuando el amor y el sufrimiento se entremezclan, como suele ocurrir, doblegan y causan un infinito dolor. Para nosotros, mortales nacidos en el siglo XX, las entrañas vienen a ser lo que en el psicoanálisis se conoce como inconsciente. ¿Y no es cierto que el apeiron es nuestro inconsciente colectivo? ¿No es ese fondo sagrado que hemos aprendido a callar, a reprimir y a dejar en la sombra?

De particular importancia es la claridad, la presencia del astro rey, de ese Apolo luminoso que se ha metamorfoseado en luz, en sol en esta primera prosa. Asimismo, representa la luz del nuevo día y la llegada de la aurora, aunque la protagonista esté en un delirio que la lleva a la finitud. Esta luz podría remitirnos a la metáfora de la luz intelectual; no obstante, Zambrano es enfática en los postulados de la razón poética de ir hacia lo oscuro, la cueva, los ínferos, las entrañas y ese recinto donde se halla el corazón humano.

En esta primera prosa, aparece también el símbolo de la sierpe, un símbolo que está presente en toda la obra zambraniana. Además, es necesario señalar que la serpiente es una constante en todas las culturas. La sierpe como alegoría alude al camino de la iniciación, el transitar humano y su entrada en la historia, mas en el texto siguiente la sierpe se enlaza con el cosmos, según se puede leer: "Pero ahora que abro los ojos, Aurora, que cerré para 
invocarte, ya no estás; ni tampoco tú, la sierpe del Sol poniente. Luz cambiante ¿me oyes, me has oído y huiste? ¿Eres tú así? ¿Así eres tú?” (1989: 40)

Hay que destacar, no obstante, que esta presencia de la fluorescencia es otra constante en toda la obra zambraniana y viene de lejos, del conocimiento que esta filósofa adquirió a través de las lecturas de Plotino, particularmente de Las Enéadas $\mathrm{y}$, por supuesto, de la claridad propia del pensamiento griego. Tal parece que María Zambrano proviene de un hondo y lejano peregrinar, como si ella estuviera dotada de un alma muy antigua.

La siguiente prosa poética que aparece en La tumba de Antígona se titula La noche. Aquí es necesario tomar en cuenta la importancia que la noche tiene en la escritura de la filósofa malagueña. Para tal efecto, transcribo un párrafo autobiográfico de Zambrano que recoge la escritora española, Clara Janés (2010) en el libro que lleva el nombre María Zambrano:Desde la sombra llameante: "La noche era el silencio, la ilusión de entrar en un lugar secreto de donde bruscamente nos habían despertado en algún momento, escapar de la violencia que la obligaba a estar presente, allí, aquí, aquí ante todos, siendo vista, sintiéndome juzgada."

En la prosa que menciono, en su delirio Antígona dice así:

Y mi corazón, como siempre, corre al encuentro de la sombra, como en la vida. Entonces, durante el día, anhelaba la noche, respiraba hacia ella. Sólo la mañana era para mí el presente, un ancho, hermoso presente, como el centro de un río; sólo en ella el latir del tiempo se acordaba con el de mis sienes, estas sienes que me avisaban con su latido al galopar del infortunio que llegaba. (1989: 41)

Aparece de nuevo, en el texto señalado, la metáfora del corazón, a la que Zambrano recurre en distintas ocasiones. Precisamente en el libro Hacia un saber sobre el alma, donde incluye la autora un fragmento de este ensayo, reivindica este saber primigenio:

¿Será una simple metáfora la "vi-
sión por el corazón"? La metáfora
de la visión intelectual ha sido -
nadie podrá negarlo- la definición
de una forma -hasta ahora la más
decisiva y fundamental- de cono-
cimiento. Podemos pasar de largo
junto a esta gran metáfora porque
sea, al parecer, más extraña, más
dada al equívoco, más misteriosa y
audaz? (1993: 51)

En líneas posteriores argumenta que el corazón ha sido todo, desde sede del pensamiento en Aristóteles, así como centro en las religiones. Además, añade:

En su asunción arrebatada, como si solamente así pudiese mostrarse a la vista y obtener un lugar, como si en la cultura occidental lo que en verdad signifique no pudiese ser aceptado sino en ese arrebato, en esa precipitación hacia arriba, en su ausencia llameante.(1993: 52) 
Ligada a la metáfora del corazón, está también el ámbito de la música, casi como una forma prenatal de lenguaje, ya que las palabras se forman en las entrañas y en este sentido me parece que se puede establecer un paralelismo entre la Antígona de Zambrano y el ensayo poético Diotima de Mantinea de la misma autora, en el que expresa lo siguiente:

Recogida en mí misma, todo mi ser se hizo un caracol marino; un oído; tan sólo oía. Y quizás creía estar hablando, cuando las palabras sonaban tan solo para mí, ni fuera ni dentro; cuando no eran ya dichas, ni escuchadas, tal como yo había soñado deberían ser las palabras de la verdad. (1993)

¿Y cuáles son las palabras de la verdad, no es cierto que son las que se forman en el murmullo, en el recinto que llamamos corazón? En realidad, y tal y como la filósofa lo expresa, esta metáfora del corazón se presenta en símbolos espaciales: "es como un espacio que dentro de la persona se abre para dar acogida a ciertas realidades" (1993).

Y Antígona, en la prosa intitulada La noche, exclama:

La desgracia golpeó con su martillo mis sienes hasta pulirlas como el interior de una caracola, hasta que fueron como dos oídos que sentían los pasos blandos de la desdicha, su presencia; esos pasos blandos con que la desdicha mucho antes de desatarse entra en nuestra cámara y viola el recinto del sueño sin mirarnos siquiera. (1989)

En ambos textos se puede establecer un paralelismo que nos remite al sonido como si nuestra vivencia prenatal fuera la música propiamente, ya que este es el lenguaje que Zambrano quiere comunicar: un lenguaje anterior a la palabra, que nos obligue a estar en un continuo renacimiento, o en un desnacer, para volver a nacer completamente. Precisamente, el concepto de desnacer hay que comprenderlo desde una perspectiva cercana al zen, como la disolución del ego.

Y así dice Antígona: "Quise oírla siempre, la voz de la piedra, la voz y el eco, esos dos hermanos que son la voz y el eco; hermana y hermano, sí. Mas las humanas voces no me dejan oírlas. Porque no escuchan, los hombres. A ellos, lo que menos les gusta hacer es eso: escuchar" (1989: 42).

En Sueño de la hermana, Zambrano deja ver la complicidad que existe entre Antígona e Ismene. No obstante, el mayor interés lo revela el símbolo de la sangre, texto que transcribo a continuación:

Estaba sobre una roca, roja de sangre, la sangre hecha ya piedra, y yo derramé mucha agua, toda la que pude sobre ella, para lavarla, a ella, a la sangre, y que corriera. Porque la sangre no debe quedarse dura como la piedra. No que corra como lo que es la sangre, la fuente, un riachuelo que se traga la tierra. La sangre no es para quedarse hecha piedra atrayendo a los pájaros de mal agüero, auras tiñosas que 
vienen a ensuciarse los picos. La sangre así, trae sangre, llama sangre porque tiene sed, la sangre muerta tiene sed, y luego vienen las condenas, más muertos, todavía más en una procesión sin fin. (1989: 46)

Si bien María Zambrano gusta del símbolo de la piedra, así como el del agua como principio generador de vida, conviene detenerse aquí en el tema de la sangre, tal y como está presente en la prosa que cito. Sin duda, la sangre representa el origen incestuoso del linaje de Edipo, y de nuevo remite de nuevo al texto sobre la metáfora del corazón, en el cual dice:

La sangre ha tenido también sus adoradores, pero no han sido arrebatados, sino ebrios. Una de las más espléndidas es Santa Catalina de Siena, adoradora de la sangre de Cristo, de quien dice estar embriagada. La sangre como el vino, embriaga. Es bebida, consumida, transfundida. Es metáfora en suma de comunión, de un culto dionisíaco, de embriaguez vital, en que se transfunde una vida divina a quien la bebe; metáfora de una sed infinita, una sed por esencia inextinguible. (1993: 52)

Al final de esta prosa, Antígona dice que su historia es sangrienta y que toda la historia está hecha de sangre. Tasa su historia particular dentro de la historia general. Dice que no puede morir porque requiere saber de dónde proviene esta sangre. Quizás habría que añadir que todos venimos al mundo salpicados por la sangre, sean incestuosas o no las vinculaciones que nos atan a todos los humanos.

En la prosa siguiente, se aprecia un singular diálogo entre Edipo y Antígona. El lenguaje utilizado por Zambrano en este texto, al igual que en toda la obra, es alusivo, se presta para distintas interpretaciones. Es necesario detenerse a observar este Edipo figurado por Zambrano. Es, sin duda, el más desdichado de todos los hombres: rey, soberano, casi dios y, por último, mendigo errabundo que va por los caminos, ciego, colmado de perplejidades y guiado por Antígona.

Este Edipo, padre que halla a su hija entre la vida y la muerte, es cuestionado por ésta, quien lo increpa preguntándole si es un dios. A lo que él responde solo diciéndole que es Edipo. De interés primordial en este diálogo resalta el hecho de que en principio, Edipo no ve; después sí recupera la capacidad de mirar. Entonces reconoce a su hija. También el padre nace aquí a la conciencia. La ceguera es el precio que pagó Edipo para ver sus propias entrañas. Es necesario señalar cómo se ve a sí mismo Edipo en el siguiente diálogo: "Mira, hija, yo era sólo una nube, una nube blanda, cálida, llevada por el viento. Y tuve que ser hombre" (1989: 51).

Aquí el padre se humaniza, vive un proceso de anagnórisis: "Un hombre, un hombre tuve que ser. Y yo era como un sueño. Yo era apenas el despertar de una luciérnaga, el parpadear de una llama, un poco de aliento, un palpitar de un corazón pálido. Yo no era casi nada. Era casi, era apenas, y tuve que ser eso: un hombre." Al leer lo que Edipo profiere, se puede observar, 
asimismo, que él siente la presencia de los dioses, quienes lo miran, lo persiguen como en tiempos primigenios antes del pensar filosófico.

Antígona hará que su vida se convierta en la ruptura de la cadena incestuosa; su sacrificio, su muerte, su lucidez darán paso a la purificación de los lazos consanguíneos; de ahí el carácter sagrado de la totalidad del texto.

La siguiente prosa lleva el título de Ana, la nodriza, y en ésta vemos aparecer la voz popular, la de los seres casi transparentes, que parecen no tener una historia, pero que manifiestan una gran vacilación. Pese al carácter simple que esta nodriza tiene, no solo por su carácter nutricio, también nos sacude su sentimiento de perplejidad cuando exclama: "Eso es, que cuando se ve tanto no se puede saber" (1993: 59).

$\mathrm{Y}$ es que Zambrano en su obra Hacia un saber sobre el alma, explica que:

la perplejidad es una debilidad del ánimo que no proviene del conocimiento sino de la relación entre el conocimiento y el resto de la vida que queda impermeable a él. Perplejo indica más bien sobrado de conocimiento. En toda perplejidad hay deslumbramiento; se está ante un conocimiento que deslumbra y no penetra." (1989: 79)

La perplejidad la reflejan Antígona y también Edipo cuando se preguntan ambos sobre su acontecer. Aquí hay que detenerse en el siguiente diálogo entre Antígona y la nodriza:
Ana: La historia, niña Antígona, te esperaba a ti, a ti. Por eso estás aquí, tan sola. Por la historia.

Antígona: ...Dime, Ana, dímelo, respóndeme, ¿me has oído? ¿Por qué historias estoy aquí: por la historia del reino, por la guerra entre mis hermanos? O por la historia del Mundo, la Guerra del Mundo, por los dioses, por Dios... (1989)

Esa entrada en la historia de Antígona es la llegada al umbral de la conciencia. No obstante, en el texto mencionado también está presente la vivencia de Zambrano respecto de la guerra civil española y el surgimiento del fascismo en la Europa de su tiempo.

De particular interés es el final de esta prosa cuando Antígona asevera que esa tumba es en realidad un telar. Cumple la tumba un proceso como el del capullo que se transforma luego en mariposa, de ahí que la propuesta de María Zambrano sea la transfiguración de la joven y no su muerte, tal y como lo señalé al inicio.

La prosa siguiente se titula La sombra de la madre. Es el encuentro de Antígona con Yocasta. El texto es verdaderamente sobrecogedor y en él Zambrano reivindica en su totalidad a la Gran Madre, Diosa y madre, arquetipo que puede mostrarnos en ocasiones su faz terrible, mas no en esta ocasión. Antígona, símbolo de la piedad, comprende y perdona. Debo decir que esta prosa, de manera especial, me llevó a experimentar un proceso catártico y junto a María Zambrano, digo: "Ay, Madre, inmensa sombra...” (1989). 
La alusión a la sombra remite de inmediato a las fuerzas inconscientes e invoca, asimismo, a la madre personal como al arquetipo que subyace en el inconsciente colectivo. Llama la atención el sentimiento de compasión de Antígona, quien le dice a su madre, entre otras palabras, las siguientes: "Y, ¿es que hay alguna Madre pura del el todo, alguna mujer pura del todo que sea madre? Tú sabes que no. Esa pureza de la Madre es el sueño del hijo. Y el hijo, a fuerza de amar su oscuro misterio, la lava" (1989).

De nuevo aquí, y en relación con el fragmento anterior, vale la pena citar a Jung, quien tiene una perspectiva importante en relación con este tema. El psicoanalista asevera que el miedo al incesto se transforma en el temor de ser devorado por la madre. Jung apunta al hecho de que "la madre" es en realidad una imago, una mera imagen física que personifica todo el inconsciente y quien penetra en este mundo, abre la puerta "hacia el reino de las madres" (Scrimieri Martín, 2014: 13). Termino la lectura de esta prosa con el texto que lo cierra: "Y ahora, ahora no sé qué me aguarda. Purificada por la sombra de mi Madre, atravesada en mí, sigo estando aquí todavía" (1989).

La harpía es el siguiente fragmento, en el cual Antígona establece un diálogo con esta figura, que representa a la Diosa de las Razones, a la araña del cerebro, que emite juicios sin llegar al centro de las entrañas.

Esa harpía razonadora representa, asimismo, la defensa de los que detentan el poder y que se colocan por encima de los pueblos. Por ello, Antígona defiende la Ley del Amor y no la del Terror cuando le dice: "Ya lo dije. Porque hay otra ley, la Ley que está por encima de los hombres y de la niña que llora como yo cuando lloré" (1989). Al despedirse de la Harpía, Antígona expresa que seguirá viva hasta que el Amor y la Piedad así lo quieran.

Aquí quiero desentrañar aún más el concepto de la piedad, tema que me inquieta y que merece ser comprendido a cabalidad. Al hablar de la piedad, Zambrano, en buena medida, recurre al pensamiento de Max Scheller y de Séneca, siendo este último el filósofo que con más hondura traza la ruta de la española. Sin embargo, en la búsqueda de la noción de piedad, necesariamente desemboqué en Sócrates, quien fue acusado de impiedad y es, precisamente en el diálogo del Eutifrón donde el filósofo discute este concepto con el adivino que da nombre a este texto. Eutifrón asevera lo siguiente en la discusión que se da entre ambos respecto de la santidad y la piedad: "Me parece a mí, Sócrates, que la piedad y la santidad son parte de lo justo, que corresponde al culto de los dioses, y que todo lo demás consiste en los cuidados y atenciones que los hombres se deben entre sí" (1871: 31).

Precisamente, asevera Zambrano, cuando Sócrates se formula la pregunta sobre la piedad, ya la filosofía había descubierto y establecido la idea del ser con Parménides. Además, se refiere al mencionado diálogo platónico y señala que: "Y así vemos en el breve diálogo, Eutifrón, algo sumamente delator de este proceso que apuntamos. La piedad se define primero con el trato adecuado con los dioses, para acabar reconocida como una virtud, es decir, un modo de ser del hombre justo" (1993: 205). 
Para la propia Zambrano, definir este sentimiento resulta torpe, de manera que voy a transcribir un fragmento que aparece en la obra Claves de la Razón Poética, en la cual cito un fragmento del ensayo de Cristina de la Cruz Ayuso titulado Acotación temática en torno a la piedad, autora que cita de manera textual a Zambrano:

La piedad es, quizá, el sentimiento inicial más amplio y hondo, algo así como la patria de todos los demás. Constituye el género supremo de una clase de sentimientos: amorosos o positivos. No es el amor propiamente dicho en ninguna de sus formas y acepciones; no es tampoco la caridad, forma determinada de la piedad descubierta por el Cristianismo; no es siquiera la compasión, pasión más genérica y difusa. Viene a ser la prehistoria de todos los sentimientos positivos. (1998: 118)

Pero ¿cómo comprender estos sentimientos? Ciertamente, el ámbito de lo racional no nos acerca a esta otra realidad, la realidad del estremecimiento, que es propiamente la del sujeto que reflexiona sobre sí mismo. De manera que hay en estas palabras de Zambrano una crítica al racionalismo y un pronunciamiento a favor de buscar (el hombre) en las zonas irracionales, zonas que la filosofía occidental ha ido dejando de lado, precisamente porque ha construido un sistema que no incorpora tales regiones de la conciencia humana. Aquí vuelve a estar presente toda la concepción de Zambrano sobre la metáfora del corazón.

La filósofa señala que la piedad viene a ser la prehistoria de todos los sentimientos positivos, de ahí que tenga en sus inicios carácter sagrado. Aquí cabe citar la Teogonía de Hesiodo, momento en el que Cronos confabula con su madre para destronar a su padre: "Madre, yo podría, lo prometo, realizar dicha empresa, ya que no siento piedad por nuestro abominable padre, pues él fue el primero en maquinar odiosas acciones" (1989).

En el ensayo titulado ¿Qué es la piedad? que aparece en El hombre y lo divino (1973), María Zambrano responde esta pregunta $y$, de tal manera, trascribo parte de esta meditación en las siguientes líneas:

En la Alegoría de la caverna vemos justamente la rebelión del hombre que no quiere ser liberado. Y en esta oscuridad de la "caverna" vivía mezclada con las sombras contrarias la piedad. ¿Es posible que ella también se revolviese ante la luz? Hoy, que venimos de un momento contrario, nos sentimos obligados a mirar este conflicto. Hemos pasado por un instante en que la piedad desdeñada por la luz, desconocida por la inteligencia, ha estado en las sombras." (1973: 201)

Sí, en efecto, el tema de la piedad no forma parte del pensar en nuestro tiempo, tiempo de guerras, de excluidos, desterrados, migrantes y exiliados por doquier. Época esta en la que el mercado lo ha invadido todo; época esta que se supone es el fin de la historia. ¿Será que hay que olvidarse del pensar? ¿Será que lo sagrado no asoma por ningún resquicio?

De la piedad hablan los cristianos, es una palabra y un concepto que están más bien 
dentro del terreno de las ideologías y de las religiones y no así en el campo filosófico, siendo que esa piedad-amor-razón con la que distinguimos a la Antígona de Zambrano, está presente, viva en nuestro diario acontecer. La piedad ha quedado en la sombra, no así en todos los seres, tampoco en quienes emigran debido a conflictos bélicos, que necesariamente deben reconocer al otro, al hermano en desgracia. Por eso y por tantas otras cosas que no enumero aquí, Myriam Bustos Arratia es el símbolo de la piedad: la he visto acceder al hermano, no obstante, nunca la he escuchado hablar de la piedad, porque esta noción no está en su pensamiento; sí en sus actos, en los episodios que la resumen y que la convierten en metáfora.

La prosa que lleva el título Los hermanos es en la que se encuentra la máxima tensión dramática de La tumba de Antígona pues, como cabe suponer, es el punto donde Polinicies y Etéocles se enfrentan, en especial por la visión del poder, poder que los divide y los lleva a la desarmonía y a la muerte.

En primer lugar, la palabra que se coloca al inicio de este diálogo entre Antígona y sus hermanos es la verdad. ¿Pero de cuál verdad habla la joven sacrificada? Aquí debemos detenernos y seguir el hilo de su pensamiento. La verdad que se revela es el origen incestuoso, la condena, el sufrimiento tenaz de Edipo, su destierro y el de sus hijos, así como el delirio y la muerte de Yocasta. Es la verdad de la culpa, la mancha del linaje. Aunque también hay otras verdades que asoman y se plasman como la lucha por el reino que deja el padre tras de sí.
Tanto Etéocles como Polinicies no se sienten atraídos por la verdad puesto que su cometido es gobernar y por ello, desde el inicio de esta prosa, Etéocles exclama:

La verdad, dices Antígona, mientras ¿qué? ¿Cómo íbamos a saberla entonces? Si nos deteníamos a buscarla, entonces, ¿quién iba a gobernar, a poner orden, a vivir? Y teníamos que vivir. Si nos paramos a mirar las cosas como son, entonces se nos van de las manos. (1989: 71)

En la Antígona de Sófocles como en la versión de Zambrano, cada uno de los hermanos disputa el poder. Etéocles está del lado de Creón y Polinicies está del lado de Antígona. Edipo ha dejado ya un reino dividido, en el que entra Creón, su cuñado, a gobernar.

Antígona, por su parte, manifiesta una actitud contraria a la guerra y al poder cuando dice:

Hay que matarse por el poder, por el amor. Hay que matarse entre hermanos por amor, por el bien de todos. Por todo. Hay que matar, matarse en uno mismo y en otro. Suicidarse en otro y en sí con la esperanza de ser perdonado por tanto crimen, por tanta muerte expandida. (1989: 72)

En estos diálogos, Antígona discute "las verdades" de sus hermanos, quienes manifiestan razones para haber luchado entre sí, tal y como ocurre en todas las guerras, y en particular durante la guerra civil española, que es la experiencia histórica que está detrás de la obra de María Zambrano. 
Antígona, por su parte, se centra en "la verdad", y aquí cabe anotar su reflexión sobre ésta: La verdad es a la que nos arrojan los dioses cuando nos abandonan.

Es el don de su abandono. Una luz que está por encima y más allá y que al caer sobre nosotros, los mortales, nos hiere. Y nos marca para siempre. Aquellos sobre quienes cae la verdad, son como un cordero con el sello de su amo. (1989: 77).

Para Antígona, la verdad es una palabra afín con la luz, con la claridad y aquí utiliza una comparación con el cordero para referirse a la asunción del sacrificio. Y es que esa verdad ha brotado de los ínferos, es verdad develada.

La prosa siguiente da cuenta de la aparición de Creón. Este, sin duda, representa el poder y la tiranía al igual que en la obra de Sófocles. En La tumba de Antígona, este rey llega a buscarla e intenta sacarla de la tumba y le dice así:

Como siempre, te adelantas a mi justicia, ahora en mi clemencia. Vengo a sacarte de esta tumba. La muerte de mi hijo, precipitado como tú, me impidió sacarte de aquí a tiempo para que celebrarais vuestras nupcias. Yo quería sólo darte una lección. (1989: 85)

Es necesario recordar que en la obra de Sófocles, el ahorcamiento de Antígona dispara las demás muertes, la de Hemón, su novio, y la de la esposa de Creón. En realidad, María Zambrano, en su obra, hace una síntesis de las tragedias del griego.
Un símbolo sobresale en esta prosa y es el de la puerta. En este sentido es notorio que la puerta esté abierta, de manera que al consultar el Diccionario de Símbolos ya citado, es notoria la siguiente definición:

Ya que en su simbolismo esta representa el lugar de paso entre dos estados, entre dos mundos, entre lo conocido y lo desconocido, la luz y las tinieblas, el tesoro y la necesidad. La puerta se abre a un misterio. Pero tiene un valor dinámico, psicológico; pues no solamente indica un pasaje, sino que invita a atravesarlo. Es la invitación al viaje hacia un más allá... (1986: 855)

En realidad, Antígona transita entre la vida y la muerte; la tumba es un lugar de meditación y de reposo final. Bien dicen que ser filósofo consiste en prepararse para la muerte, y en su encierro en la tumba eso es lo que Antígona hace. Para Albert Camus, la muerte es el único tema sobre el cual vale la pena pensar.

En este viaje de Antígona, es importante observar que Zambrano recoge todas las teorías de las correspondencias, presentes entre los gnósticos y también en el pensamiento de Emanuel Swedenborg, de manera que lo que ocurre arriba también tiene su réplica abajo. La puerta abierta en la tierra es la puerta abierta en el cielo.

En esta prosa, Creón intenta convencer a Antígona de que suba, que vaya hacia arriba donde están los vivos. Pero como ella va en tránsito se opone. Este pasaje me hizo evocar el Evangelio de San Mateo cuando el demonio intenta cautivar a Jesús a quien 
le ofrece todas las mieles que da el poder. Antígona se mantiene intacta, su inocencia y su pureza virginal son más fuertes que las razones que emanan del poder.

La siguiente prosa se titula Antígona. En esta, la joven monologa. Está casi al punto de irse, de transformarse, transfigurarse. La meditación de Antígona, en este caso, se refiere primeramente a la ley que prevalece, ley impuesta por Creón. La prosa, escrita desde una profundidad poética sin par, toca muy diversos temas: la muerte de Hemón, su novio e hijo de Creón quien no resucitará aunque ella ascienda tal y como se lo pide el tirano.

Las palabras que Antígona le dirige al sol constituyen un acto de deslumbramiento. En realidad, en esta prosa la joven está despidiéndose y al hacerlo reflexiona en los términos siguientes:

Y yo me quedaré aquí como una lámpara que se enciende en la oscuridad. Tendría que ir todavía más abajo y hundirme hasta el centro mismo de las tinieblas, que muchas han de ser. Para encenderme dentro de ellas. Pues que sólo me fío de esa luz que se enciende dentro de lo más oscuro y hace de ello un corazón. Allí nunca llegó la luz del sol que nos alumbra. Sí; una luz sin ocaso en el centro de la eterna noche. (1989: 90)

Sin duda, Antígona manifiesta el deslumbramiento, mas también observa la realidad donde se mezclan la luz y la oscuridad. Contrasta la metáfora de la lámpara que ilumina todo su ser y especialmente sus entrañas. Hay, por así decirlo una luminosidad externa y otra interna y es que ella ha tocado el fondo de sí misma, su centro.

En esta prosa, Antígona contrapone la nueva ley a la vieja ley, la de Creón. Si hubiese una nueva ley donde se establezca la piedad y el trato justo, entonces ella ascendería; no obstante, tal hecho no ocurrió.

Habla la joven también del exilio, del destino aciago que tuvo que vivir guiando a su padre de tierra en tierra. Uno de los textos más encomiables de esa condición de exiliada es el siguiente:

Porque llevábamos algo que allí, allá, donde fuera, no tenían; algo que no tienen los habitantes de ninguna ciudad, los establecidos; algo que solamente tiene el que ha sido arrancado de raíz, el errante, el ser que se encuentra un día sin nada bajo el cielo y sin tierra; el que ha sentido el peso del cielo sin tierra que lo sostenga. (1989)

La prosa final se titula Dos desconocidos. Aparecen dos hombres, figuras fantasmagóricas también, que además son difíciles de interpretar. Por una parte, podría tratarse de hombres del pueblo que vienen a sacarla de la tumba. Al leer una y otra vez el texto, la dualidad de los desconocidos hace pensar en Cástor y Pólux. No obstante, el papel que juegan estos sin nombre recuerdan la figura de Orfeo cuando fue en busca de Eurídice. En realidad, todo este texto final está colmado de enigmas. El desconocido segundo es el que logra sacar a Antígona y esta se marcha diciendo: 
“Ah, sí. ¿Dónde? ¿Adónde? Sí, Amor. Amor tierra prometida." (1989: 98).

¿Será que va a una tierra soñada, a una patria utópica en la que encontrará a su prometido o llegará a una tierra donde impere la nueva ley, donde se congreguen los hermanos?

Para finalizar, luego de realizar esta lectura, donde el tema de la piedad es fundamental, me detengo, asimismo, a reflexionar sobre el tema que más me ha inquietado desde hace décadas: la conjunción entre poesía y filosofía que no es tan frecuente hallarla. María Zambrano traza ese camino de unión y, en especial, en La tumba de Antígona, quizás su obra más literaria, aunque a decir verdad, todo su pensamiento filosófico está colmado de poesía, precisamente porque logró esa sabia síntesis.

Aquí quiero detenerme unos instantes para transcribir y dejar abierto este tema, el cual, entre muchos, ella recoge en el tomo titulado Filosofía y poesía, libro editado por primera vez en México en el año 1939.

Al inicio, la filósofa señala que han existido mortales afortunados, en los que convergen poesía y pensamiento. Diríamos que el caso de Dante es uno de ellos, así como ciertos poetas románticos alemanes. En esta obra ella apunta aquí las divergencias que a continuación cito directamente:

Pero hay otro motivo más decisivo de que no podamos abandonar el tema y es que hoy poesía y pensamiento se nos aparecen como dos formas insuficientes; y se nos antojan dos mitades del hombre: el filósofo y el poeta. No se encuentra el hombre entero en la filosofía; no se encuentra la totalidad de lo humano en la poesía. En la poesía encontramos al hombre concreto, individual. En la filosofía el hombre en su historia universal, en su querer ser. La poesía es encuentro, don, hallazgo por gracia. La filosofía busca, requerimiento guiado por un método. (1996: 13)

En el párrafo siguiente, la autora profundiza más en el tema cuando habla de la entablada lucha que se da al respecto en la época de Platón quien, como sabemos, hace una condenación de la poesía. De ahí que Zambrano explica que: "Desde que el pensamiento consumó su "toma de poder, la poesía se quedó a vivir en los arrabales, arisca y desgarrada diciendo a voz en grito todas las verdades inconvenientes, terriblemente indiscretas y en rebeldía" (1996: 14).

Verdades inconvenientes nos revela Antígona. Quizás hablar de la piedad, del trato justo, del "otro", de ese desconocido, de ese excluido, anónimo, errante y sumido en los arrabales, sea una forma de ahondar en verdades y en la búsqueda de una patria de hermanos, una patria común, una patria de todos.

Muchas gracias 


\section{Bibliografía}

Chevalier, Jean y Alain Gheebrant. Diccionario de símbolos. Barcelona: Herdes, 1986.

De la Cruz Arjuso, Cristina. Acotación temática en torno a la piedad. Claves de la razón poética. Madrid: Editorial Trotta, 1998.

Del Olmo Campillo, Gemma. La voz de Antígona en María Zambrano: entre la vida y la muerte. En Juan Manuel Araguiés Estragués y Jesús Esquema Gómez (coords.), De Heidegger al postestructuralismo: panorama de la ontología y la antropoñogía contemporáneas. Madrid, 2014.
Eliade, Mircea. Mitos, sueños y misterios. Barcelona: Editorial Kairos, 2001. Hesiodo. Teogonía. Madrid: Gredos.

Janés, Clara. María Zambrano: Desde la sombra llameante. Madrid: Siruela, 2010.

Platón. Obras completas. Vol. 1. Madrid: Patricio de Azcánate, editor, 1871-1872.

Scrimieri Martín, Rosario. Los mitos y Jung. Internet. Recuperado: 6 de setiembre de 2014.

Zambrano, María. El hombre y lo divino. $2^{\mathrm{a}}$. ed. México: FCE, 1973. La tumba de Antígona. Barcelona: Mondadori, 1989. Hacia un saber sobre el alma. España: Alianza Tres, 1993. Filosofía y poesía. México: FCE, 1996. 